\title{
Characteristic of LED light curing unit and classification by generation for clinicians
}

\author{
Young-Bo Shim, An-Na Choi, Jeong-Kil Park* \\ Department of Conservative Dentistry, School of Dentistry, Pusan National University, Yangsan, Republic of Korea
}

Since light curing composite resin was introduced in the 1960s, light curing process has been considered as an essential process. Herein, various light sources became available for the process. Quartz-tungsten-halogen (QTH) light curing units (LCUs) dominated the market until the 1990s, before the LED LCUs started replacing them in the 2000s. The LED, developed approximately 50 years ago, came into use in the dentistry field from the late 1990s, and the LED LCUs, with the 2000s. Since then, the LED LCUs have gone through many advancements to its current fourth generation. In accordance to such advancements of the LED light curing unit, the majority of light curing unit used today are LED LCUs. As much as its usage has increased, it is necessary that dental clinicians understand the characteristics of the device. The objective of this review report is to provide the history of the scientific development and describe the characteristics of the LED LCUs. (J Dent Rehabil Appl Sci 2017;33(4):245-51)

Key words: LED; light curing unit; characteristic; generation

\section{서론}

1960년대 후반 광중합 레진이 소개된 이후 레진은 구 강내 환경에서 안정적으로 유지되며, 환자들의 심미적 요 구의 증대로 현재 가장 널리 사용되고 있는 수복재료이 다. 광중합 레진의 중합 개시제로는 camphoroquinone (CQ)과 삼차 아민이 주로 사용되며 레진이 적절히 잘 중 합되기 위해서 광중합기는 중요하며 이에 따라 중합기에 대한 많은 연구들이 진행되고 있다. ${ }^{1,2}$

1970년대 quartz bulb를 가지고 가시광선 영역의 빛을 내는 중합기가 처음 생산되었다. 처음 소개된 광중합기 에서 발전하여 Quartz-tungsten-halogen (QTH) 중합기 가 1990년대까지 널리 사용되었다. 하지만, 크고 휴대하 기가 불편한 단점을 가지고 있다.

다음으로 소개된 plasma arc (PAC) 중합기는 높은 출

*Correspondence to: Jeong-Kil Park

Professor, Department of Conservative Dentistry, School of Dentistry, Pusan National University, 20 Geumo-ro, Mulgeum, Yangsan, Gyeongnam, 50612, Republic of Korea

Tel: +82-51-360-5221, Fax: +82-51-360-5214, E-mail: jeongkil@pusan.ac.kr Received: July 17, 2017/Last Revision: October 20, 2017/Accepted: October 24, 2017
\end{abstract}

력과 넓은 범위의 파장으로 3 초의 중합으로도 충분하다 고 소개되었지만 3 초의 시간으로는 레진의 중합이 적절 하게 이루어지지 못하는 것이 밝혀졌으며, 얼마 사용되지 못하고 시장에서 사라졌다. ${ }^{1}$

2000년대 들어서 Light emitting-diode (LED) 광중합 기가 개발되어 사용되기 시작하였으며, 현재 사용되는 중합기의 대부분은 LED 광중합기이다. ${ }^{1-3}$ 본 연구의 목 적은 현재 널리 사용되는 LED 광중합기의 역사와 특징 들에 대하여 문헌 고찰을 통해 살펴보는 것이다.

\section{문헌고찰}

\section{History of LED LCU}

반도체를 이용하여 만들어진 LED 전구는 작고 배터

Copyright@ 2017 The Korean Academy of Stomatognathic Function and Occlusion. (c) It is identical to Creative Commons Non-Commercial License. 
리를 이용해서도 빛을 낼 수 있으며 오랫동안 사용할 수 있으며 현재까지 $\mathrm{LED}$ 는 우리 생활의 일부가 되었다. 이 러한 여러 가지 장점들이 치과영역에 적용되어 LED 광 중합기가 시장에 출시되게 되었다. ${ }^{2} \mathrm{LED}$ 광중합기가 시 장에 출시된 이후 계속해서 발전하였으며 중합기의 세대 별 분류는 많은 문헌들에서 광중합기의 발전에 따라 구 분하고 있다. ${ }^{1,2}$

2000년에 들어와 LED 광중합기가 시장에 처음으 로 출시되었다. 1 세대 광중합기는 여러 개의 LED가 합 쳐져서 출력을 내는 중합기들이다. ${ }^{1,2}$ 처음 시판된 $\mathrm{LED}$ 광중합기는 LuXoMAX (Akeda Dental A/S, Lystrup, Denmark)라는 제품으로 7 개의 LED가 합쳐져 있으 며, 충전식으로 휴대가 가능하였다. 하지만 첫 LED 광 중합기는 QTH 광중합기보다 낮은 출력으로 효과적 이지 못했다. ${ }^{2,4} 2001$ 년 출시된 Elipar ${ }^{\mathrm{TM}}$ FreeLight (3M/ ESPE, St. Paul, USA)는 19개의 LED가 합쳐진 것으로 $400 \mathrm{mw} / \mathrm{cm}^{2}$ 의 출력을 나타내었고 제조사는 $800 \mathrm{mw} /$ $\mathrm{cm}^{2}$ 의 출력을 갖는 QTH 광중합기와 비슷한 성능이라 고 주장하였다. ${ }^{2,5}$ 이 외에도 GC에서 출시된 E-light (GC Corp., Tokyo, Japan)는 64개의 LED가 합쳐진 것으로 $360 \mathrm{mw} / \mathrm{cm}^{2}$ 의 출력을 나타냈다. ${ }^{6}$ 하지만, 이러한 1 세대 $\mathrm{LED}$ 광중기는 QTH 광중합기와 비교해서 더 높은 출력 과 우수한 중합 효과를 나타내지 못하였다. ${ }^{1,2,6}$

2세대 LED 광중합기는 LED 기술의 발전에 따라 하 나의 LED 만으로도 충분히 높은 출력을 낼 수 있게 되어 서 한 개의 $\mathrm{LED}$ 만이 장착된 광중합기이며, 현재까지도 많이 사용되고 있다. 각 회사들은 구강내에 적용하기 편 한 형태의 디자인을 제안하였으며, 여러가지 다양한 형태 의 디자인들이 출시되었다. ${ }^{2} 1000 \mathrm{mw} / \mathrm{cm}^{2}$ 의 출력을 낼 수 있는 막대 형태의 Elipar ${ }^{\mathrm{TM}}$ FreeLight2 (3M/ESPE)가 $3 \mathrm{M}$ 에서 출시되었다. ${ }^{6,7}$ Dentsply에서 출시된 SmartLite ${ }^{\mathrm{TM}}$ PS (Dentsply/DeTrey, Konstanz, Germany)는 약 950 $\mathrm{mw} / \mathrm{cm}^{2}$ 의 출력을 나타낸다고 제조사는 설명하고 있으 며 작고 휴대하기 편한 pen형태였다. ${ }^{8}$ 한편, 2005년 Kerr 에서 출시된 L.E. Demetron II (Kerr Corp., Orange, USA)는 QTH 광중합기와 비슷한 gun 형태로 냉각 팬 을 내장하여 열을 분산할 수 있는 디자인을 선택하였고 $1200-1600 \mathrm{mw} / \mathrm{cm}^{2}$ 의 출력을 나타낼 수 있다고 제조 사는 설명하였다. ${ }^{9}$ 2006년 coltene에서 출시된 Coltolux LED (Coltene/Whaledent Inc., Cuyahoga Falls, USA) 는 막대 형태로 $1400 \mathrm{mw} / \mathrm{cm}^{2}$ 의 출력을 나타낸다고 제 조사는 설명하고 있다. ${ }^{10}$ 초기에 출시된 2 세대 $\mathrm{LED}$ 중
합기를 보완하고 출력 강도를 높인 중합기들이 출시되 었다. ${ }^{1,2}$ Elipar $^{\mathrm{TM}}$ S10 (3M Oral Care, St. Paul, USA)은 평행한 glass fiber light guide를 사용하여 빛이 분산되 지 않고 나아갈 수 있다고 제조사는 설명하였으며 출력 은 $1200 \mathrm{mw} / \mathrm{cm}^{2}$ 였고, 형태를 유지하면서 디자인에 약 간 변화를 주고 출력을 $1500 \mathrm{mw} / \mathrm{cm}^{2}$ 까지 높인 Elipar ${ }^{\mathrm{TM}}$ DeepCure-S (3M Oral Care)가 2016년 출시되었다. ${ }^{11,12}$ 2011년에 Kerr에서 출시된 Demi Plus (Kerr Corp.)는 막대 형태로 PLS (Periodic Level Shifting) 기술을 적용 하여 중합시간동안 $1100 \mathrm{mw} / \mathrm{cm}^{2}$ 에서 $1320 \mathrm{mw} / \mathrm{cm}^{2}$ 의 출력을 주기적으로 반복 적용하여 이러한 기술이 온도 상승을 억제하면서 중합 효율을 높인다고 제조사는 설명 하였다. ${ }^{13}$ 2012년 Dentsply에서 출시된 SmartLite Focus (Dentsply, Milford, USA)는 curing tip에 focus lens를 부 착해 빛의 손실을 줄이고 레진과 거리가 $8 \mathrm{~mm}$ 까지 떨어 져 있어도 효과적이라고 제조사는 설명하였다. ${ }^{14}$ 2세대 초기 광중합기들은 현재 대부분 시판되지 않고 있으며, 발전된 형태의 2세대 중합기들이 시판되고 있다.

3세대 LED 광중합기는 우리가 일반적으로 polywave 라고 부르는 중합기로 하나의 중합기의 tip에서 여러 파 장의 빛을 방출한다. ${ }^{1,2}$ 레진의 중합 개시제로 $\mathrm{CQ}$ 가 가장 많이 사용되지만 레진 제조사들은 레진 중합을 위한 광 개시제로 $\mathrm{CQ}$ 뿐 아니라 $\mathrm{CQ}$ 보다 짧은 파장에서 빛을 흡 수하는 1-phenyl-1,2-propanedione (PPD)같은 부가 중 합 개시제를 첨가하게 되었다. 그러므로 2세대의 single peak LED로는 부가 중합 개시제가 첨가된 레진의 충분 한 중합이 어렵게 되었다. ${ }^{2}$ 그래서 광중합기 제조사들은 이러한 문제의 해결을 위해 단일 파장이 아닌 둘 또는 세 개의 파장에서 peak 값을 갖는 LED 광중합기를 개발하 게 되었으며 이를 polywave라고 부르게 되었다. 이러한 형태의 $\mathrm{LED}$ 는 $\mathrm{CQ}$ 뿐 아니라 부가 중합 개시제의 적절 한 파장에 영향을 미쳐 좀 더 효과적으로 중합이 이루어 지는 것을 목표로 하였다. ${ }^{1,2}$ 2003년에 Ultradent에서 처 음으로 시장에 출시한 polywave 광중합기인 Ultralume 5 (Ultradent, South Jordan, USA)는 pen 형태로 가운데 하나의 파란색 파장의 빛을 내는 LED 와 주변에 보라색 파장의 빛을 내는 네 개의 LED 로 이루어져 있다. ${ }^{15} 2006$ 년 GC에서 출시된 G-Light (GC Corp.)는 하나의 보라 색 파장의 빛을 내는 $\mathrm{LED}$ 와 일곱 개의 파란색 파장의 빛 을 내는 $\mathrm{LED}$ 로 구성된 광중합기로 gun 형태였다. ${ }^{16,17}$ 또 한 Ivoclar Vivadent에서는 Bluephase G2 (Ivoclar Vivadent, Schaan, Liechtenstein)와 Bluephase style (Ivoclar 
Vivadent)을 출시하였다. Bluephase G2는 gun 형태이며 하나의 보라색 파장의 빛을 내는 LED와 세 개의 파란 색 파장의 빛을 내는 LED로 구성되어 있고, Bluephase style은 하나의 보라색 파장의 빛을 내는 LED와 두 개 의 파란색 파장의 빛을 내는 $\mathrm{LED}$ 로 구성되어 있으며 손 에 잡기 쉬운 막대 형태로 제작되어 사용자의 편의를 고 려하였다고 제조사는 설명하고 있다. ${ }^{18,19}$ 이후 근래에 출 시된 polywave 중합기로 Bluephase 20i (Ivoclar Vivadent), Bluephase style 20i (Ivoclar Vivadent), VALO (Ultradent, South Jordan, USA)가 있다. Bluephase 20i 와 Bluephase style 20i는 Bluephase G2와 Bluphase style과 같은 형태이며 Turbo mode를 추가하여 순간적
으로 $2000 \mathrm{mw} / \mathrm{cm}^{2}$ 이상의 빛을 방출한다. ${ }^{20,21} \mathrm{VALO}$ 는 하나의 보라색 파장, 두 개의 푸른색 파장, 하나의 푸른 색보다 더 긴 파장의 빛을 내는 $\mathrm{LED}$ 로 구성되어 있어서 세 부분에서 peak 값을 갖는 특징이 있으며 최대 출력은 $3200 \mathrm{mw} / \mathrm{cm}^{2}$ 인 막대 형태이다. ${ }^{22}$

4세대 중합기로 일컬어지는, 2012년 출시된 Scanwave (Acteon-Satelec, Merignac, France)는 4개의 서로 다른 파장을 가진 빛이 고정되지 않고 계속해서 switching 되 며 빛을 방출한다. ${ }^{23,24}$ 현재 출시된 4 세대 LED 광중합기 는 Scanwave가 유일하며 계속적으로 출시를 지켜봐야 할 것이다. 언급된 LED 광중합기들이 Table 1에 정리되 어 있다.

Table 1. Classification of LED LCUs

\begin{tabular}{|c|c|c|c|c|}
\hline Generation & Curing Light & Manufacturer & $\begin{array}{l}\text { Irradiance } \\
\text { (Intensity) }\end{array}$ & $\begin{array}{l}\text { Cure time option } \\
\text { (Seconds) }\end{array}$ \\
\hline \multirow[t]{3}{*}{$1 \mathrm{st}$} & LuXoMAX & Akeda Dental A/S & $100 \mathrm{mw} / \mathrm{cm}^{2}$ & \\
\hline & Elipar ${ }^{\mathrm{TM}}$ FreeLight & $3 \mathrm{M} / \mathrm{ESPE}$ & $400 \mathrm{mw} / \mathrm{cm}^{2}$ & \\
\hline & E-light & GC & $360 \mathrm{mw} / \mathrm{cm}^{2}$ & \\
\hline \multirow[t]{8}{*}{2 nd } & SmartLite $^{\mathrm{TM}}$ PS & Dentsply & $950 \mathrm{mw} / \mathrm{cm}^{2}$ & $10 \mathrm{~s}$ \\
\hline & Elipar ${ }^{\mathrm{TM}}$ FreeLight & $3 \mathrm{M} / \mathrm{ESPE}$ & $1000 \mathrm{mw} / \mathrm{cm}^{2}$ & \\
\hline & L.E. Demetron II & Kerr & $1200-1600 \mathrm{mw} / \mathrm{cm}^{2}$ & $5,10,20,30 \mathrm{~s}$ \\
\hline & Coltolux LED & coltene & $1400 \mathrm{mw} / \mathrm{cm}^{2}$ & \\
\hline & Elipar $^{\mathrm{TM}} \mathrm{S} 10$ & 3M Oral Care & $1200 \mathrm{mw} / \mathrm{cm}^{2}$ & $5,10,15,20 \mathrm{~s}$ \\
\hline & Elipar ${ }^{\mathrm{TM}}$ DeepCure-S & 3M Oral Care & $1500 \mathrm{mw} / \mathrm{cm}^{2}$ & $5,10,15,20 \mathrm{~s}$ \\
\hline & Demi Plus & Kerr & $1100-1320 \mathrm{mw} / \mathrm{cm}^{2}$ & \\
\hline & SmartLite focus & Dentsply & $1400 \mathrm{mw} / \mathrm{cm}^{2}$ & $20 \mathrm{~s}$ \\
\hline \multirow{6}{*}{$\begin{array}{c}3 \text { rd } \\
\text { (polywave) }\end{array}$} & Ultralume 5 & Ultradnet & $800 \mathrm{mw} / \mathrm{cm}^{2}$ & \\
\hline & Bluephase G2 & Ivoclar Vivadent & $\begin{array}{l}\text { Soft start: } 650 / 1200 \mathrm{mw} / \mathrm{cm}^{2} \\
\text { Low power: } 650 \mathrm{mw} / \mathrm{cm}^{2} \\
\text { High Power: } 1200 \mathrm{mw} / \mathrm{cm}^{2}\end{array}$ & $5,10,15,20,30 \mathrm{~s}$ \\
\hline & Bluephase style & Ivoclar Vivadent & $1200 \mathrm{mw} / \mathrm{cm}^{2}$ & $5,10,15,20 \mathrm{~s}$ \\
\hline & Bluephase 20i & Ivoclar Vivadent & $\begin{array}{l}\text { Soft start: } 650 / 1200 \mathrm{mw} / \mathrm{cm}^{2} \\
\text { Low power: } 650 \mathrm{mw} / \mathrm{cm}^{2} \\
\text { High Power: } 1200 \mathrm{mw} / \mathrm{cm}^{2} \\
\text { Turbo: } 2000 \mathrm{mw} / \mathrm{cm}^{2}\end{array}$ & $5,10,15,20,30 \mathrm{~s}$ \\
\hline & Bluephase style $20 \mathrm{i}$ & Ivoclar Vivadent & $\begin{array}{l}\text { High Power: } 1200 \mathrm{mw} / \mathrm{cm}^{2} \\
\text { Turbo: } 2000 \mathrm{mw} / \mathrm{cm}^{2}\end{array}$ & $5,10,15,20 \mathrm{~s}$ \\
\hline & Valo & Ultradnet & $\begin{array}{l}\text { Standard: } 1000 \mathrm{mw} / \mathrm{cm}^{2} \\
\text { High power: } 1400 \mathrm{mw} / \mathrm{cm}^{2} \\
\text { Xtra power: } 3200 \mathrm{mw} / \mathrm{cm}^{2}\end{array}$ & $5,10,15,20 \mathrm{~s}$ \\
\hline 4th & Scanwave & ACTEON & $\begin{array}{l}\text { Active: } 1500 \mathrm{mw} / \mathrm{cm}^{2} \\
\text { Standard: } 1250 \mathrm{mw} / \mathrm{cm}^{2}, \\
2200 \mathrm{mw} / \mathrm{cm}^{2} \\
\text { Supercharged: } 2000 \mathrm{mw} / \mathrm{cm}^{2}, \\
3000 \mathrm{mw} / \mathrm{cm}^{2}\end{array}$ & $\begin{array}{l}\text { Scan mode: } 9,20 \mathrm{~s} \\
\text { Bonding mode: } 5,60 \mathrm{~s}\end{array}$ \\
\hline
\end{tabular}


최근 인터넷에서도 구입이 쉬운 2 세대 광중합기에 속 한다고 볼 수 있는 LED 광중합기들이 있다. Budget 광 중합기라고 불리며 기존의 광중합기와 비교되지 않을 정 도로 저렴한 가격으로 구매할 수 있지만 아직까지는 효 과적인 성능을 기대하기는 어렵다. ${ }^{25}$

\section{Characteristics of LED LCU}

광중합기에서 방출하는 빛의 특성을 이해하기 위해서 는 몇몇 용어들을 이해하고 있어야 한다. 임상가들이 광 중합기에 관해서 알아야 할 용어들이 Table 2에 정리되어 있다. Radiant power, irradiance, spectral radiant power 에 대해서는 기본적으로 이해하고 있어야 한다. Radiant power는 단위시간당 전달한 에너지로 단위는 $\mathrm{W}$ 또는 $\mathrm{J} / \mathrm{s}$ 를 사용하여 일정 시간 동안 전달할 수 있는 에너지 를 나타낸다. Irradiance는 단위면적당 출력으로 단위는 $\mathrm{mW} / \mathrm{cm}^{2}$ 를 사용하여 일정한 면적에 전달할 수 있는 에 너지를 나타낸다. Spectral radiant power는 단위 파장에 서 나타나는 출력으로 단위는 $\mathrm{mW} / \mathrm{nm}$ 를 사용하여 일정 한 파장에서 전달하는 에너지를 나타낸다. ${ }^{3}$

$\mathrm{CQ}$ 는 460 에서 $470 \mathrm{~nm}$ 파장 범위에서 가장 높은 활 성을 나타내는 광개시제이다. LED 광중합기는 QTH나 $\mathrm{PAC}$ 에 비해 좁은 파장 범위에서 큰 출력을 나타내어 $\mathrm{CQ}$ 의 중합 개시에 더욱 효율적이다. 또한, polywave 광중합 기는 $405 \mathrm{~nm}$ 와 $455 \mathrm{~nm}$ 에서 높은 출력을 나타내 QTH 나 PAC 광중합기에 비해 레진에 포함된 부가 중합 개시 제에 더욱 효과적으로 에너지를 전달 할 수 있다.

세 가지 광중합기를 소구치에 중합했을때의 irradiance 를 살펴보면, Elipar S10은 비교적 균일한 출력을 나타 내며 전반적으로 효과적으로 에너지를 전달한다. Bluephase G2는 polywave로 $4500 \mathrm{mw} / \mathrm{cm}^{2}$ 가 넘는 높은 출 력 부분이 있는가 하면, $400 \mathrm{mw} / \mathrm{cm}^{2}$ 보다 낮은 출력 부 분이 혼재한다. Budget 광중합기인 Woodpecker LED.
B (Guilin Woodpecker Medical Instrument Co, Ltd, Guangxi, China)는 균일하지 못하며 광중합기의 팁보다 좁은 범위로 빛이 전달된다. ${ }^{25}$ 그러므로 출력 범위를 고려 할 때 2 세대 광중합기의 사용이 아직까지는 가장 효율적 으로 생각되며, polywave는 더욱 균일한 출력을 나타내 기 위한 연구가 더욱 필요해 보인다.

레진 중합시 레진의 온도가 $1^{\circ} \mathrm{C}$ 상승할 때마다 반응률 이 $1.9 \%$ 증가한다는 것은 알려져 있으며, 광중합기를 켜 고 광중합을 시작한 1 초 후에 레진의 초기 온도는 $22^{\circ} \mathrm{C}$ 에서 $35^{\circ} \mathrm{C}$ 로 상승하여 반응률이 2 배가 된다는 것이 보고 되었다. ${ }^{26,27}$ 온도가 높아지면 레진의 중합은 낮은 온도보 다 더 빠르게 응력을 만든다. ${ }^{28}$ 레진의 중합은 발열의 중 합반응과 광조사 동안 흡수된 빛에너지로부터의 온도 상 승을 모두 반영한다. 균일하지 못한 중합기의 온도 변화 의 영향과 중합이 시작된 후 너무 빨리 높아진 온도는 레 진의 중합이 균일하지 못하게 일어나고 내부에 응력이 급속하게 일어나는 부정적인 영향을 미치게 된다. ${ }^{29}$ 그러 므로, 출력이 균일하여 온도 변화의 분포가 균일한 중합 기를 선택해야 할 것이며, 중합 초기에 급속한 온도 상승 을 줄이기 위해 soft-start 방법 등을 사용하여야 할 것이 다.

$\mathrm{LED}$ 광중합기들은 모두 배터리를 사용하며 배터리 충전 수준에 영향을 받게 된다. 기존의 유수한 회사들의 제품들은 대부분 배터리의 충전 수준이 낮아져도 일정한 출력을 유지하며, 베터리의 충전 수준이 일정 수준 이하 가 되면 즉시 사용자에게 알려준다. 하지만, budget 광중 합기들은 배터리가 낮아지게 되면 이에 영향을 받아 출 력 또한 낮아지게 된다. ${ }^{25}$ 그러므로, budget 광중합기를 사용한다면 베터리 충전 수준이 떨어지지 않도록 유의하 여야 할 것이며 기존의 유수한 회사들의 제품은 배터리 의 충전 수준 낮아져도 출력이 유지된다고는 하지만 배 터리 충전 경고가 뜨면 즉시 충전을 해주어야 할 것이다. 이외에도 LED 전구의 수명이 수천시간이라고 알려져 있

Table 2. Terms for Comprehension ${ }^{3}$

\begin{tabular}{lll}
\hline \multicolumn{1}{c}{ Term } & \multicolumn{1}{c}{ Symbol } & Notes \\
\hline Radiant energy & $\mathrm{J}$ & Energy \\
Radiant flux or radiant power & $\mathrm{W}$ or J/s & Radiant energy per unit of time \\
Irradiance (incident irradiance) & $\mathrm{mW} / \mathrm{cm}^{2}$ & It reflects an average value over the total surface area \\
Spectral radiant power & $\mathrm{mW} / \mathrm{nm}$ & Radiant power per wavelength \\
Spectral irradiance & $\mathrm{mW} / \mathrm{cm}^{2} / \mathrm{nm}$ & Irradiance per wavelength \\
\hline
\end{tabular}


지만 오랫동안 사용시 출력이 낮아질 수 있다. 광중합기 의 출력을 측정할 수 있는 radiometer가 시중에 시판되고 있다. QTH radiometer가 처음 출시되었고, LED 광중합 기가 시장에 출시된 후에는 LED radiometer가 출시되었 다. LED radiometer는 좁은 파장 범위의 빛을 측정하여 QTH radiometer보다 좀 더 정확성을 높였다고 제조사 는 설명하고 있다. 하지만, 현재 출시된 radiometer들이 광중합기의 정확한 출력을 측정하기는 어렵지만, 출력의 변화를 보여줄 수는 있어서 출력이 낮아지는 상태를 확 인할 수는 있다. ${ }^{30}$ 그러므로, 광중합기의 출력을 정기적 으로 측정해주어 출력이 낮아지지 않도록 유의하여야 할 것이다.

\section{결론}

LED 광중합기는 현재 레진 광중합의 기본 기기로 자 리 잡았다. 앞에서 살펴본 것처럼 LED 광중합기는 4세 대까지 발전해왔다. 현재 주로 사용되고 있는 LED 광중 합기들은 주로 2 세대와 3 세대의 제품들이다. 균일한 파 장의 빛을 내는 2 세대 광중합기와 2 개 혹은 3 개의 서로 다른 파장의 빛을 내는 3 세대 광중합기들은 각각의 장단 점과 특성을 가지고 있다. 임상가들은 앞서 언급한 여러 가지 광중합기의 세대별 제품들의 특징을 알고 자신이 사용하기 적합한 광중합기를 선택해서 좀 더 효율적으로 사용해야 할 것이다.

\section{ORCID}

Young-Bo Shim https://orcid.org/0000-0003-4730-2711

An-Na Choi https://orcid.org/0000-0003-0364-4621

Jeong-Kil Park https://orcid.org/0000-0001-6333-8138

\section{References}

1. Rueggeberg FA. State-of-the-art: dental photocuring - a review. Dent Mater 2011;27:39-52.

2. Jandt KD, Mills RW. A brief history of LED photopolymerization. Dent Mater 2013;29:605-17.

3. Price RB, Ferracane JL, Shortall AC. Light-curing units: a review of what we need to know. J Dent Res 2015;94:1179-86.

4. Topcu FT, Erdemir U, Sahinkesen G, Yildiz E, Uslan I, Acikel C. Evaluation of microhardness, surface roughness, and wear behavior of different types of resin composites polymerized with two different light sources. J Biomed Mater Res B Appl Biomater 2010;92:470-8.

5. Elipar ${ }^{\mathrm{TM}}$ FreeLight Product Brochure 2002. 3M ESPE.

6. Tsai PC, Meyers IA, Walsh LJ. Depth of cure and surface microhardness of composite resin cured with blue LED curing lights. Dent Mater 2004;20: 364-9.

7. $3 \mathrm{M}$ ESPE. Elipar ${ }^{\mathrm{TM}}$ FreeLight 2 Product Brochure 2003. Available form: http://multimedia.3m.com/ mws/media/191434O/elipar-freelight-2-technicalprofile-english.pdf (updated 2017 DEC 14).

8. DENTSPLY DeTrey. SmartLite ${ }^{\mathrm{TM}}$ PS Brochure 2004. Available form: http://www.dentsply.de/ bausteine.net/f/7047/SCSmartLite030902.pdf (updated 2017 DEC 14).

9. Kerr. L.E.Demetron II. Product Brochure 2005.

10. David JR, Gomes OM, Gomes JC, Loguercio AD, Reis A. Effect of exposure time on curing efficiency of polymerizing units equipped with lightemitting diodes. J Oral Sci 2007;49:19-24.

11. 3M Oral Care. Elipar ${ }^{\mathrm{TM}} \mathrm{S} 10$ Product Brochure 2010. Available form: http://multimedia.3m.com/mws/ media/575877O/elipartm-s10-led-curing-light.pdf (updated 2017 DEC 14).

12. $3 \mathrm{M}$ Oral Care. Elipar ${ }^{\mathrm{TM}}$ DeepCure-S Product Brochure 2016. Available form: https://multimedia.3m. $\mathrm{com} / \mathrm{mws} / \mathrm{media} / 1173327 \mathrm{O} /$ elipar-deepcure-ledcuring-lights-technical-product-profile.pdf (updated 2017 DEC 14).

13. Kerr. Demi Plus Product Brochure 2011. Available form: https://www.kerrdental.com/kerr-restoratives/demi-plus-dental-curing-lights (updated 2017 DEC 14).

14. DENTSPLY. SmartLight ${ }^{\mathrm{TM}}$ Focus Brochre 2012. Available form: http://www.smartlitefocus.com (updated 2017 DEC 14).

15. Ultradent Products Inc. Ultralume 5 Brochure 2003.

16. GC corp. G-Light Brochure 2006.

17. Price RB, Labrie D, Rueggeberg FA, Felix CM. Irradiance differences in the violet $(405 \mathrm{~nm})$ and blue $(460 \mathrm{~nm})$ spectral ranges among dental light-curing units. J Esthet Restor Dent 2010;22:363-77. 
18. IvoclarVivadent. Bluephase ${ }^{\circledR}$ G2 Brochure 2009. Available form: https://www.ivoclarvivadent.us/ explore/bluephase-g2 (updated 2017 DEC 14).

19. IvoclarVivadent. Bluephase ${ }^{\circledR}$ Style Brochure 2013. Available form: https://www.ivoclarvivadent.us/ explore/bluephase-style (updated 2017 DEC 14).

20. IvoclarVivadent. Bluephase ${ }^{\circledR} 20$ i Brochure 2011. Available form: https://www.ivoclarvivadent.us/ explore/bluephase-20i (updated 2017 DEC 14).

21. IvoclarVivadent. Bluephase ${ }^{\circledR}$ Style $20 \mathrm{i}$ Brochure 2016. Available form: https://www.ivoclarvivadent. us/explore/bluephase-style-20i (updated 2017 DEC 14).

22. Ultradent Products Inc. Valo Brochure 2011. Available form: https://www.ultradent.com/en-us/Dental-Products-Supplies / equipment/VALO-LEDCuring-Lights/VALO-Cordless/Pages/default.aspx (updated 2017 DEC 14).

23. ACTEON. ScanWave product Brochure 2010. Available form: https://www.acteongroup.com/uken/my-products/equipment/polymerization/miniled-scanwave (updated 2017 DEC 14).

24. Shortall AC, Palin WM, Jacquot B, Pelissier B. Advances in light-curing units: four generations of
LED lights and clinical implications for optimizing their use: Part 2. From present to future. Dent Update 2012;39:13-22.

25. AlShaafi MM, Harlow JE, Price HL, Rueggeberg FA, Labrie D, AlQahtani MQ, Price RB. Emission characteristics and effect of battery drain in "Budget” curing lights. Oper Dent 2016;41:397-408.

26. Hiemenz PC, Lodge TP. Polymer chemistry. 2nd ed. Boca Raton; CRC Press; 2007.

27. Price RB, Whalen JM, Price TB, Felix CM, Fahey J. The effect of specimen temperature on the polymerization of a resin-composite. Dent Mater 2011; 27:983-9.

28. Watts DC, Alnazzawi A. Temperature-dependent polymerization shrinkage stress kinetics of resincomposites. Dent Mater 2014;30:654-60.

29. Stahl F, Ashworth SH, Jandt KD, Mills RW. Lightemitting diode (LED) polymerisation of dental composites: flexural properties and polymerization potential. Biomaterials 2000;21:1379-85.

30. Roberts HW, Vandewalle KS, Berzins DW, Charlton DG. Accuracy of LED and halogen radiometers using different light sources. J Esthet Restor Dent 2006;18:214-22; discussion 223-4. 


\section{임상가가 알아두면 유용한 LED 광중합기의 특성과 세대별 분류}

\section{심영보, 최안나, 박정길*}

부산대학교 치의학전문대학원 치과보존학교실

1960년대 광중합 레진이 소개된 이후 현재의 수복학에서 광중합은 중요한 과정으로 고려되고 있다. 광중합을 위한 다 양한 중합기들이 소개되어서 발전하면서 사용되어져 왔다. Quartz-tungsten-halogen (QTH) 광중합기는 1990년도까지 널리 사용되었으며 2000년 들어 LED 광중합기가 널리 사용되고 있다. 1세대 LED 광중합기는 여러 개의 LED가 출력 을 내는 광중합기로 QTH 광중합기에 비해 높은 출력을 내짐 못했다. 2세대 LED 광중합기는 하나의 LED로도 충분한 출력을 낼 수 있게 되었으며, camphoroquinone (CQ) 이외에 부가 중합개시제를 고려하여 3세대 polywave 중합기가 시 장에 출시되었다. 현재는 LED에서 방출하는 빛이 계속 switching되는 4세대 광중합기가 개발되어 출시되었다. 이러한 $\mathrm{LED}$ 광중합기의 발전에 따라 사용하는 광중합기의 대부분이 LED 광중합기로 자리잡고 있다. LED 광중합기의 사용 의 증가에 따라 임상가들은 광중합기의 특성을 이해하고 있어야 한다. 본 리뷰 논문의 목적은 LED 광중합기에 대한 세 대별 분류와 특징에 대한 정보를 주기 위함이다.

(구강회복응용과학지 2017;33(4):245-51)

주요어: LED; 광중합기; 특성; 세대

*교신저자: 박정길

(50612) 경남 양산시 물금읍 금오로 20 부산대학교 치과대학 치과보존학교실

Tel: 055-360-5211 | Fax: 055-360-5214 | E-mail: jeongkil@pusan. ac. kr

접수일: 2017년 7월 17일 | 수정일: 2017년 10월 20일 | 채택일: 2017년 10월 24일 